\title{
Frequency of ischemic stroke in patients with bacterial meningitis visiting to Jinnah Postgraduate Medical Center Karachi. Cross-sectional study
}

\author{
Saira Awan' ${ }^{1}$, Khalid Sher ${ }^{2}$, Samar IItaf ${ }^{3}$, Quratulain Panhwar ${ }^{4}$ \\ ${ }^{1}$ Neurology, Altibiri Medical College, Karachi, Pakistan \\ ${ }^{2}$ Neurology, Jinnah Postgraduate Medical Center, Karachi, Pakistan \\ ${ }^{3}$ Neurology at Dow University of Health Sciences, Karachi, Pakistan \\ ${ }^{4}$ Neurology, Tabba Hospital. Karachi, Pakistan
}

\begin{abstract}
Objective. To determine the frequency of ischemic stroke in patients presenting with bacterial meningitis visiting to JPMC.

Material and method. Descriptive cross-sectional study, held in Neurology ward of Jinnah Postgraduate Medical Centre, Karachi, from 20thapril 2018 to 20th October 2018. Patients aged $>18$ years of either gender with acute bacterial meningitis were included, written informed consent was obtained from all participants and also approval of ethical review committee of the institute was obtained. CT scan brain or MRI brain performed in all the included patients to assess ischemic stroke. All the collected data were recorded on proforma. The data was analysed using SPSS version 20.

Results. 168 patients of bacterial meningitis were included. Mean \pm SD of age was $63.48 \pm 10.53$ (61.87-65.08) years. Out of 168 patients, $118(70.28 \%)$ were male and $50(29.76 \%)$ were female. The frequency of ischemic stroke in patients with bacterial meningitis was found to be $22(13.09 \%)$. In stratification of age group, $18-40$ years and $>40$ years, ischemic stroke was found in $4(6.2 \%)$ and $18(17.3 \%)$ patients respectively.

In stratification of gender frequency of ischemic stroke in patients with bacterial meningitis in our study was found to be (16.9\% among males and $4 \%$ among females).

Conclusions. The frequency of ischemic stroke in patients with bacterial meningitis was $13.09 \%$ and it is associated with poor outcome so high degree of suspicion is necessary for timely diagnosis and treatment of this life threatening complication. Ischemic stroke was found to be significantly more common in old patients as compared to young adults, also more common in males as compared to females.
\end{abstract}

Keywords: bacterial meningitis, ischemic stroke, nervous system, Pakistan

\section{INTRODUCTION}

Acute bacterial meningitis is defined as inflammation of meninges (protective covering of brain), several types of bacteria can cause meningitis but most common pathogens in adults include Streptococcus pneumoniae, Neisseria meningitides, Haemophilus influenzae. Most common clinical features are eever, headache and neck rigidity, other features include nausea, vomiting, drowsiness, confusion delirium and coma, but up to $95 \%$ of patients have 2 of four features including fever, headache, neck stiffness and altered level of consciousness [1].
World Health Organization defined stroke is as rapidly developing clinical signs of focal (or global) disturbance of cerebral function, with symptoms lasting $\geq 24 \mathrm{~h}$, or leading to death, with no apparent cause other than of vascular origin [2]. The incidence of acute bacterial meningitis is variable in different parts of the world. In developed countries incidence of acute bacterial meningitis is between 0.7 and 0.9 per 100,000 , but due to less access to preventive measures such as vaccination and poor hygienic conditions its incidence is 40 per 100,000 in developing countries [3]. There are certain risk fac- 
tors for ABM out of which most important include extremes of age (infants and older age $>65$ years), immunocompromised state, HIV infection, malignancy, diabetes mellitus, splenectomy or hyposplenism, solid organ transplant recipients. Acute bacterial meningitis is a life threatening condition worldwide. With timely diagnosis and treatment, the mortality for $H$. influenzae and Neisseria meningitidis infections decreased to $<10 \%$, and for $S$. pneumoniae to $30 \%$ [5]. Although effective treatment with antibiotics, steroids and intensive care, as well as advent of conjugated vaccines for three most common causative agents has significantly reduced morbidity and mortality associated with $A B M$, but still ABM remains important health issue specially in developing countries [6]. If ABM is not timely diagnosed and treated can lead to serious complications, common acute neurological complications in descending order of frequency include cerebrovascular disease(ischaemic stroke), cerebral oedema, hydrocephalus, and intracerebral haemorrhage $[7,8]$. Previously localized cerebral vasculitis (mostly involving small penetrating arteries) was thought to be sole cause of cerebrovascular ischemia [9], but studies suggests that other factors can also be responsible [10-12]. In developed countries, multiple studies have been done to determine frequency of ischaemic stroke in adult patients with acute bacterial meningitis $[13,14]$, but there is a need for more population-based studies in Asian countries like Pakistan as no research has been done in this subject as per our knowledge. The results from this study will help in better planning by healthcare professionals for prompt diagnosis and management of ischemic stroke in acute bacterial meningitis patients. The purpose of this study is to determine the frequency of ischemic stroke in bacterial meningitis because it is a poor prognostic sign. As large number of populations in Pakistan belongs to rural areas and poor socio-economic status, mostly patients reported very late with presentation of bacterial meningitis due to lack of medical facilities and financial constraints therefore are at high risk of ischemic stroke as compared to other developed countries. This study will add the recent and local magnitude of ischemic stroke among patients presenting with bacterial meningitis in existing pool of literature, so that strategies can be made for further research in this respect and also to prevent and timely manage this deadly complication.

\section{MTERIAL AND METHODS}

The data of our study was collected from the neurology unit of Jinnah Postgraduate Medical Centre, Karachi. The patients aged 18-80 years of either gender with CSF suggestive of acute and subacute bacterial meningitis admitted in the neurology unit were included.

Patients with cerebral venous sinus thrombosis, tuberculous meningitis, brain abscess, subarachnoid hemorrhage, intra-cerebral bleed, tumor, trauma, other systemic diseases like chronic renal failure, cardiac failure, chronic liver disease, sepsis, recent history of any brain surgery were excluded from this study.

Acute bacterial meningitis presented with (headache, fever, neck stiffness, petechiae, confusion or altered level of consciousness) and at least one of the following: positive culture of CSF; positive blood culture and at least one of the independent predictors of bacterial meningitis in the CSF detail report: more than 2000 leukocytes/l and predominantly neutrophil count, glucose index less than 0.23 , CSF glucose less than $1.9 \mathrm{mmol} / \mathrm{l}$, protein greater than $2.2 \mathrm{~g} / \mathrm{l}$; presence of bacteria on AFB smear and Gram stain of the CSF studies.

The definition of acute ischemic stroke is the sudden onset of focal neurological deficit presenting within 24 hours, with at least one of the following symptoms: sudden onset contralateral weakness or numbness of body, dysphasia or aphasia, sudden blurring of vision or decrease in the level of consciousness, and the findings on the computerized tomography (CT) scan brain showing hypodense area (which will appear as black) or no it might present with no abnormality. MRI brain shows diffusion restriction on DWI image. The study sample was selected through non-probability, consecutive sampling method.

After taking approval from ethical review committee of the institute, the study was conducted. All patients admitted in the department of Neurology JPMC, Karachi, with acute bacterial meningitis that were fulfilling the inclusion criteria were included in this study. The purpose of the study, risk factors, and the benefit of the study were explained to the attendants of the patients and informed consent was taken from the Patient and attendants. CT scan and MRI brain was performed to all the included patients to assess the outcome variable i.e. ischemic stroke. All the data was be collected by the researcher herself and entered into the predesigned proforma.

The sample size of the study was calculated using WHO sample size calculator. Previous studies show the prevalence of ischemic stroke in acute bacterial meningitis as $9.8 \%$. This is coupled with confidence level of $95 \%$, and margin of error $4.5 \%$. The sample required to meet the objective comes out to be $n=168$ patients of acute bacterial meningitis. 
The data was be analyzed by using SPSS version 20. Mean and SD was be calculated for quantitative variable like age. The frequencies and percentages were calculated for categorical variables like age, gender and outcome variable for ischemic stroke in (yes or no). The data was stratified on the basis of age and gender to see the effect of these on outcome variables. The Chi-Square was applied using $\mathrm{p} \leq$ 0.05 as significant.

\section{RESULTS}

In our study, 168 patients were included to assess the frequency of ischemic stroke in patients presenting with bacterial meningitis and the results were analyzed as mean \pm standard deviation of age was $63.48 \pm 10.53$ with C.I (61.87-65.08) years as in Table 1. Out of the 168 patients, 118 (70.24\%) were men and 50 (29.76\%) were women as shown in figure 1. The frequency of ischemic stroke in patients with bacterial meningitis was found to be 22 (13.09\%) as shown in figure 2. In stratification of age group (18-40 and > 40), ischemic stroke was found in $4(6.2 \%)$ and 18 (17.3\%) patients respectively (table 2) and $p$ value found to be significant i.e. $(p=$ 0.039), as shown in table 3 . In stratification of gender frequency of ischemic stroke in patients with bacterial meningitis in the present study was found to be (16.9\% among males and $4 \%$ among females).

TABLE 1. Descriptive statistics of age

\begin{tabular}{|l|l|}
\hline Mean & $\mathbf{6 3 . 4 8}$ (years) \\
\hline $\pm S D$ & 10.53 \\
\hline 95\% confidence interval & $61.87-65.08$ \\
\hline Median & 63.00 \\
\hline Range & 50 \\
\hline
\end{tabular}

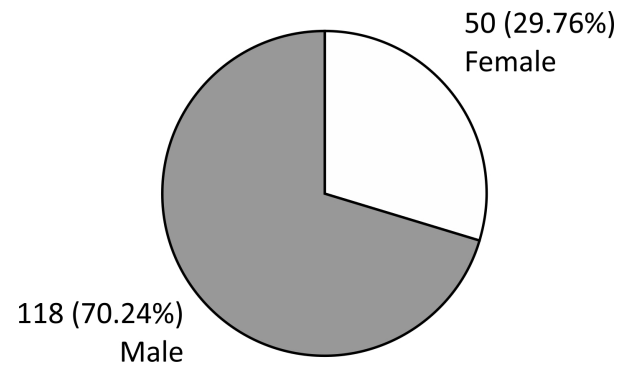

FIGURE 1. Distribution of gender

TABLE 2. Stratification of age group with respect to ischemic stroke

\begin{tabular}{|l|c|c|c|}
\hline \multirow{2}{*}{ Age group [Years] } & \multicolumn{2}{|c|}{ Ischemic stroke } & \multirow{2}{*}{ p value } \\
\cline { 2 - 3 } & yes & no & \multirow{2}{*}{0.039} \\
\hline $18-40$ & $4(6.2 \%)$ & $60(93.8 \%)$ & \\
\hline$>40$ & $18(17.3 \%)$ & $86(82.7 \%)$ & \\
\hline
\end{tabular}

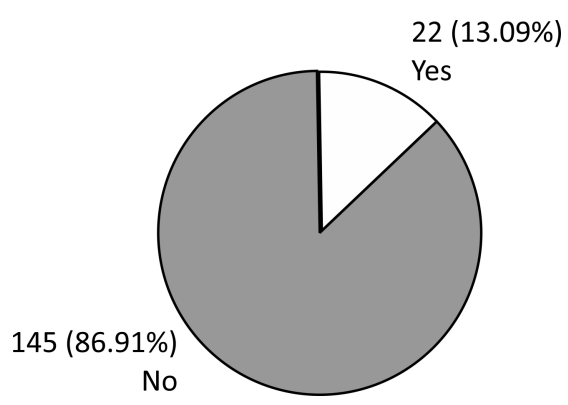

FIGURE 2. Frequency of ischemic stroke

TABLE 3. Stratification of gender with respect to ischemic stroke $\mathrm{n}=168$

\begin{tabular}{|l|l|l|l|}
\hline \multirow{2}{*}{ Gender } & \multicolumn{2}{|l|}{ Ischemic stroke } & P-value \\
\cline { 2 - 3 } & yes & no & 0.023 \\
\hline Male & $20(16.9 \%)$ & $98(83.1 \%)$ & \\
\hline Female & $2(4 \%)$ & $48(96 \%)$ & \\
\hline
\end{tabular}

\section{DISCUSSION}

Stroke is one of the most important cause of mortality and morbidity. Its incidence increases with age and is more common in men than women [15]. In our study, mean age of patient was 63.48 years, which is greater than 60.8 years reported by Khan et al. [16] and slightly lower than 70 years as in United States [17]. This is due to better awareness programs and control of the risk factors in United States, but in Pakistan patients have shorter life span. The male to female ratio of 2.36:1 in this study, which is slightly higher as compared to that reported by Khealani et al. [18]. In our study, we have found that stroke is more common (13.09\%) in bacterial meningitis. The most common risk factors for cerebral infarction in meningitis are extremes of age, immunocompromised patients, altered consciousness at the time of admission, deranged inflammatory markers, and seizures $[13,14]$.

The exact pathogenesis of cerebral vascular infarction in bacterial meningitis is still uncertain. In the adult patients with bacterial meningitis, cerebral arteriopathy is suggested in $50-80 \%$ on transcranial doppler ultrasound $[19,20]$. From studies it is found out that the greater the host immune reactions the higher likelihood of stroke [21]. We have found out that in almost half of the cases with stroke the most predominant bacterial pathogen was Streptococcus pneumoniae (55\%). Infective endocarditis to be a rare underlying condition $(n=3)$ in our study, and although meningococcal meningitis has been associated with disseminated intravascular coagulopathy but it is associated with low risk for stroke [22,23]. The adverse risk factors for the patients with stroke are extremes of age, patient to be in a comatose state at the time of admission, and to have episodes of seizures at the time of admission. In our study we have observed that the increase 
tendency towards the higher mortality is decrease consciousness, and more long-term sequelae in survivors than in patients without stroke. Our research study findings are in more favor of previous studies regarding the incidence of stroke in community acquired bacterial meningitis (9-17\%) [24,25], but as compared to the other two studies the incidence is somewhat lower in our study [26,27]. In the first study the incidence of stroke was 25\% it also included cerebral infarctions (no ischemic changes on CT scan brain) that are accounting for almost twothirds of the cases. The total of $71 \%$ of the patients were included in that study. The other study included tuberculous meningitis cases that is also associated with the increasing incidence of cerebrovascular infarctions. The findings in our study are consistent with previous case reports including etiology, clinical features and laboratory studies, and the increasing mortality and morbidity rates in community acquired bacterial meningitis with and without cerebro-vascular accident [28,29].

This study is the first study to examine the association between age and gender with cerebrovascular infarction in patients with bacterial meningitis.
The main limitation of our study was limited outcomes selected in our study affects the worth of our study. There were many variables and factors that have association with our predictor and outcome variables that could have been included in our study. The use of non-probability sampling also limits generalizability; however, we had selected smaller number of patients and besides the follow up duration was short. This study was single hospital-based study; so the final result does not reflect the exact frequency and severity of the disease.

\section{CONCLUSIONS}

Stroke is one of the most fatal complication of bacterial meningitis, there is a need to screen all patients admitted with bacterial meningitis for ischemic stroke and these patients likely to have an unfavorable outcome. It is to be concluded that frequency of ischemic stroke in patients with bacterial meningitis was found to be $13.09 \%$. However, there is a need to conduct more studies using large sample size with multiple study sites in Pakistan to validate these results.

\section{REFERENCES}

1. Hasbun R. Meningitis. Available at: https://emedicine.medscape.com/ article/232915-overview.

2. Khealani BA, Khan M, Tariq M, Malik A, Siddiqi Al, Awan S, et al. Ischemic strokes in Pakistan: observations from the national acute ischemic stroke database. J Stroke Cerebrovascular Dis. 2014;23:1640-7.

3. Brouwer MC, van de Beek D. Epidemiology of community-acquired bacterial meningitis. Curr Opin Infect Dis. 2018;31(1):78-84.

4. Adriani KS, Brouwer MC, van de Beek D. Risk factors for communityacquired bacterial meningitis in adults. Neth J Med. 2015;73(2):53-60.

5. Swartz MN. Bacterial meningitis - a view of the past 90 years. N Engl J Med. 2004;351:1826.

6. van de Beek D, Brouwer M, Hasbun R, et al. Community-acquired bacterial meningitis. Nat Rev Dis Primers. 2016;2:16074.

7. Vergouwen MDI, Schut ES, Troost D, et al. Diffuse cerebral intravascular coagulation and cerebral infarction in pneumococcal meningitis. Neurocrit Care. 2010;13(2):217-227.

8. Schut ES, Lucas MJ, Brouwer MC, et al. Cerebral infarction in adults with bacterial meningitis. Neurocrit Care. 2012;16(3):421-427.

9. Swartz MN, Dodge PR. Bacterial meningitis - a review of selected aspects. 1. General clinical features, special problems and unusual meningeal reactions mimicking bacterial meningitis. N Engl J Med. 1965;272:842-8.

10. Weisfelt M, Determann RM, de Gans J, van der Ende A, Levi M, van de Beek D, et al. Procoagulant and fibrinolytic activity in cerebrospinal fluid from adults with bacterial meningitis. J Infect. 2007;54:545-50.

11. Muller M, Merkelbach S, Huss GP, Schimrigk K. Clinical relevance and frequency of transient stenoses of the middle and anterior cerebral arteries in bacterial meningitis. Stroke. 1995;26:1399-1403.

12. Chow F, Marra C, Cho T. Cerebrovascular disease in central nervous system infections. Semin Neurol. 2011;31:286-306.

13. Schut ES, Lucas MJ, Brouwer MC, Vergouwen MDI, van der Ende A, van de Beek D. Cerebral infarction in adults with bacterial meningitis. Neurocritical Care. 2011;16(3):421-427.

14. Katchanov J, Heuschmann PU, Endres M, Weber JR. Cerebral infarction in bacterial meningitis: predictive factors and outcome. J Neurol. 2009;257:716-20.

15. Toyoda K, Yasaka M, Nagata S, Yamaguchi T. Aortogenic embolic stroke: a transesophageal echocardiographic approach. Stroke. 1992 Aug;23(8):1056-61.

16. Khan $\mathrm{H}$, Afridi AK, Ashraf S. A hospital-based study on stratification of risk factors of stroke in Peshawar. Pak J Med Sci. 2006;22(3):304.

17. Powers WJ, Rabinstein AA, Ackerson T, et al.; American Heart Association Stroke Council. 2018 Guidelines for the Early Management of Patients With Acute Ischemic Stroke: A Guideline for Healthcare Professionals From the American Heart Association/American Stroke Association. Stroke. 2018 Mar;49(3):e46-e110.

18. Khealani BA, Hameed B, Mapari UU. Stroke in Pakistan. J Pak Med Assoc. 2008;58(7):400.

19. Ries S, Schminke U, Fassbender K, Daffertshofer M, Steinke W, Hennerici M. Cerebrovascular involvement in the acute phase of bacterial meningitis. J Neurol. 1997;244(1):51-55.

20. Müller M, Merkelbach S, Huss GP, Schimrigk K. Clinical relevance and frequency of transient stenoses of the middle and anterior cerebral arteries in bacterial meningitis. Stroke. 1995;26(8):1399-1403.

21. Bodilsen J, Dalager-Pedersen M, Schønheyder HC, Nielsen H. Stroke in community-acquired bacterial meningitis: a Danish population-based study. Int J Infect Dis. 2014;20:18-22.

22. Stephens DS, Hajjeh RA, Baughman WS, Harvey RC, Wenger JD, Farley MM. Sporadic meningococcal disease in adults: results of a 5 -year population-based study. Ann Intern Med. 1995;123:937-40.

23. van de Beek D, de Gans J, Spanjaard L, Weisfelt M, Reitsma JB, Vermeulen M. Clinical features and prognostic factors in adults with bacterial meningitis. N Engl J Med. 2004; 351(18):1849-59.

24. Ferri FF. Ferri's differential diagnosis: a practical guide to the differential diagnosis of symptoms, signs, and clinical disorders. Elsevier Health Sciences; 2010. 
25. Naess, H., Waje-Andreassen, U. Review of long-term mortality and vascular morbidity amongst young adults with cerebral infarction. Eur J Neurol. 2010;17:17-22.

26. Neau JP, Ingrand P, Mouille-Brachet $C$, et al. Functional recovery and social outcome after cerebral infarction in young adults. Cerebrovasc Dis. 1998; 8:296-302.

27. Bamford J, Sandercock P, Dennis M, et al. Classification and natural history of clinically identifiable subtypes of cerebral infarction. Lancet. 1991;337:1521-6.
28. Stephens DS, Greenwood B, Brandtzaeg P. Epidemic meningitis, meningococcaemia, and Neisseria meningitidis. Lancet.

2007;369:2196-210

29. van de Beek D, de Gans J, Tunkel AR, Wijdicks EF. Community-acquired bacterial meningitis in adults. N Eng/ J Med. 2006;354:44-53. 